\title{
LA COMPAÑIA DE LIBREROS E IMPRESORES DE VALENCIA: FINANZAS Y CULTURA EN EL SIGLO XVIII
}

Ricardo FRANCH

Universidad de Valencia

y Antonio MESTRE

Universidad de Alicante 

La característica fundamental de la compañia, que el 30 de noviembre de 1759 formaron en Valencia cinco mercaderes de libros y tres impresores, deriva del tipo de asociación que adoptaron, es decir, el constituir una sociedad por acciones. El desarrollo de este tipo de sociedades en la España del siglo XVIII resulta de enorme interés, puesto que contrasta con la forma más habitual con la que los comerciantes solian unir sus capitales y esfuerzo para la consecución de sus fines, utilizando un tipo de compañias que eran conocidas como generales o "colectivas", o, con menor frecuencia, las comanditarias(1). El carácter personalista que con ellas se imprimía al capitalismo de la época era también compartido a nivel legal, puesto que en las Ordenanzas del Consulado de Bilbao de 1737, que directamente o a través de su influencia en otras ordenanzas particulares solían regir la mayor parte de la actividad comercial española, sólo se regulaban estas formas de asociación comercial, mientras que las compañias por acciones ni siquiera eran citadas, no recibiendo de hecho ningún tipo de regulación general hasta el Código de Comercio de 1829(2). Sin embargo, eran éstas las que de una forma más directa contenían los rasgos jurídicos tipicos de la futura empresa capitalista.

Según señala F. Galgano(3), su origen deriva de las compañias privilegiadas para la explotación colonial creadas por los estados europeos en los siglos XVII-XVIII, siendo fruto, por tanto, de la politica mercantilista que, por medio de la división del capital en acciones, consiguió movilizar unos enormes recursos que con las formas tradicionales de asociación dificilmente se hubieran logrado. La España del siglo XVIII también fue pródiga en la creación de estas grandes compañías. Pero su carácter frecuentemente artificial, y, sobre todo, sus privilegios y su tendencia exclusivista en la explotación de un determinado mercado o de un producto redundaban a la larga en perjuicio del propio desarrollo capitalista, paladín de la industria privada. De ahí que resulte interesante el estudio de las compañias por acciones que sin el carácter privilegiado ni el apoyo estatal comenzaron a surgir en la España de la segunda mitad del siglo XVIII, intentando observar en ellas los rasgos que anuncian a las futuras sociedades anónimas. 
En este aspecto, la aportación de la compañia de libreros e impresores de Valencia es muy importante, sobre todo en dos cuestiones: en primer lugar, porque contrasta en su finalidad con la mayoría de las sociedades privadas por acciones creadas en la España de la segunda mitad del XVIII, orientadas fundamentalmente hacia el campo de los seguros marítimos y ubicadas, por tanto, en las principales plazas de comercio, es decir, Barcelona, Cádiz o Bilbao. Y en segundo lugar, por su precocidad temporal, ya que si en Cataluña este tipo de sociedades surgieron fundamentalmente en la década de 1770-80(4), en Cádiz la primera que se ha localizado corresponde a 1763(5), y en Bilbao los dos ejemplos encontrados son de fecha posterior a 17706), en nuestro caso, la compañia aquí estudiada corresponde a 1759 , siendo anterior incluso a la sociedad creada con la misma finalidad en Madrid en 1763, aunque E. Larruga señala que ésta fue una continuación de otra que anteriormente habian formado cuatro o cinco individuos (7). Desde luego estas dos compañias no dejaban de obedecer a una necesidad derivada de la mentalidad mercantilista imperante. Asi se expresaba en el caso de la compañía de Valencia, ya que en la exposición de motivos de su acta de constitución se señalaba que ésta se habia creado "...con el fin del adelantamiento de las imprentas de la misma y del comercio de sus librerias... y solicitar, si pueden, entrar en obras de mayor utilidad de las que se introducen de los Reynos extranjeros....(8). Una finalidad similar señalaba E. Larruga para la compañía de impresores y libreros de Madrid, sobre la que decía "...Luego que se juntaron los impresores y mercaderes de libros de Madrid, tomaron la laudable determinación de formar compañía por la cual se facilitase el caudal necesario para hacer impresiones en el Reyno, y privar a los extranjeros en parte de las muchas ganancias que sacaban con los libros que nos introducian para nuestro uso.... (9). Por tanto la necesidad de fomentar las fábricas nacionales para evitar la competencia extranjera, que fue también el objetivo de las grandes compañias. Pero se diferencian claramente de aquéllas en que, aunque quizás fuesen alentadas por los poderes públicos, no pretendían lograr ningún tipo de privilegios ni tenían un carácter exclusivista. La ausencia de estos factores es lo que permite calificarlas como sociedades por acciones de tipo privado y abordar el estudio de sus características fundamentales para compararlas con las actuales sociedades anónimas. 
Los rasgos fundamentales que diferencian a las sociedades anónimas de las existentes anteriormente son: su naturaleza capitalista frente al personalismo imperante en aquéllas; y el grado de responsabilidad limitada de sus socios, en contraste con la anterior responsabilidad ilimitada de éstos frente a las deudas sociales. Conviene, pues, analizar estos aspectos en el caso de la compañía aquí estudiada para poderla calificar adecuadamente.

El primer rasgo a observar es la naturaleza de la compañía para poder apreciar su carácter personalista o capitalista. El hecho de que el capital social esté dividido en acciones no es determinante en este aspecto, puesto que no resulta infrecuente encontrar compañias de tipo general que dividen su capital en varias participaciones, pero a la hora de distribuir éstas entre sus miembros sigue atendiéndose a su consideración personal para poder ser integrados o no en la compañia. Es decir, en las compañías de tipo colectivo es la solvencia, el buen nombre y la trayectoria del comerciante lo que suele ponderarse, siendo el capital aportado a la compañía un aspecto secundario, al menos a los ojos del público. Este hecho se refleja claramente en el nombre que adopta la sociedad, es decir, la urazón social", en la que suelen combinarse la mayoría de los nombres o apellidos de los socios, soliendo ir por delante el nombre del comerciante principal o el del que posea una mayor solvencia o una trayectoria personal más nítida. La desaparición de la importancia de la consideración personal del socio en la compañia es lo que acerca a ésta hacia un carácter más eminentemente capitalista. $Y$ este rasgo se puede apreciar perfectamente en el caso de la compañía estudiada. En primer lugar por la ausencia de una razón social personalista. En ella no se citan sus integrantes, sino que alude a una "compañía de libreros e impresores de la ciudad de Valencia". Desde luego, en el capítulo primero parece apreciarse una cierta restricción al señalarse que «...serán admitidas todas las (acciones) que ofrezcan los libreros e impresores de esta ciudad...", pero ésta deriva más de la finalidad intrinseca de la compañía (la impresión y venta de libros) que no de una selección de los socios por su consideración personal. Este hecho se aprecia mejor en su capítulo quinto, en el que versando sobre la posibilidad de enajenación de acciones (aspecto en el que nos detendremos posteriormente) se dispone que "...no siendo librero o impresor en quien 
recaiga la acción, o acciones, no tendrá voto en la compañia, ni podrá obtener empleo en ella...". Por tanto, la restricción que se realiza en contra de las personas ajenas a aquellos oficios deriva de la necesidad de que la compañia esté regida y dirigida por los miembros cuya actividad profesional esté más próxima al fin propuesto por la compañía.

Otro aspecto en el que se refleja el personalismo de una compañia es en la forma de gestión. Lo más habitual en las sociedades generales es que en su gestión participen directamente todos sus miembros, de ahí que también se las conozca como sociedades "colectivas". Aunque los sistemas de administración podian ser el disyuntivo (cualquier socio puede actuar en nombre de la compañia), el conjunto (todos los socios deben participar para que un contrato afecte a la compañía) y el repartido (se atribuye a cada socio un tipo de negocio en el que actuará en representación de lá compañia), el más habitual era el primero, tanto por las facilidades que reportaba para una contratación ágil, como por la confianza que los socios debian tener entre si(10). Este rasgo personalista también desaparece en las compañias por acciones, ya que la gestión colectiva es abandonada en favor de la delegada. Es decir, los socios no participan directamente en la administración de la compañia, sino que nombran unos cargos directivos que se encargan de ella por un tiempo determinado, siendo supervisados por la junta de accionistas. En nuestro caso era el capítulo sexto el que establecía los cargos de la compañía, que se componían de dos directores, dos depositarios y un contador, quien asumiria además el papel de secretario. Estos cargos serían elegidos por todos los accionistas «...a excepción de los que no sean libreros e impresores...", y tendrán una duración de tres años, desde el día de San Andrés, al término de los cuales cabria la posibilidad de ser reelegidos (capitulo séptimo). Las funciones de los directores estaban delimitadas en el capitulo once, y consistian en acudir al Consejo a pedir las licencias de impresión de libros, elegir y comprar el papel, nombrar los correctores, y, en general, “...hacer todas las diligencias precisas hasta dejar la impresión en poder del depositario, y avisar a los interesados estar concluidas...». Por su parte, los depositarios eran encargados de custodiar uno el dinero y otro los libros impresos (capítulo quince). Finalmente, el secretario contador estaba encargado de llevar los libros, uno de juntas, donde se anotasen los acuerdos tanto de 
las reuniones particulares de los cargos directivos como de las generales de accionistas, y otro de cuentas para anotar el dinero y papel que entre y salga del depósito (capítulo $24 .{ }^{\circ}$ ). El resto de los accionistas estaban totalmente desligados de la administración, limitándose a ser convocados para aprobar las cuentas anuales en junta general (capitulo $9 .^{\circ}$ ) 0 a ser oídos cuando los directores quisieran convocar junta general para decidir algunas cuestiones (capitulo 17. ${ }^{\circ}$ ). A pesar de ello, los accionistas que fuesen libreros o impresores tenian un protagonismo mucho mayor, pues debian ser convocados en junta "...antes de empezar alguna impresión..." para decidir por mayoría de votos (capítulo $10 .^{\circ}$ ). Por tanto, los socios quedan un tanto al margen de la gestión directa de la empresa, a pesar de esta mayor participación de los socios libreros e impresores, encargándose de ella unos administradores delegados.

Sin embargo, los dos rasgos hasta ahora analizados (la ausencia de razón social en la que se integren sus miembros y la no participación directa de los socios en la gestión de la empresa) no son elementos excluyentes que permitan calificar por si mismos a una sociedad como no personalista, puesto que estos factores también aparecen en las compañias comanditarias, en las que el socio comanditario no suele aparecer en la razón social, que sólo recoge a los socios "complementarios" o colectivos, quienes son también los que se encargan exclusivamente de la dirección de la empresa(11). El rasgo que realmente diferencia a una compañia capitalista de otra personalista es la posibilidad de transmisión o enajenación de las acciones, es decir, el hecho de que la acción sea negociable(12). Analizando este hecho en el caso de la compañía estudiada podremos apreciar realmente su naturaleza. Desde luego, como norma general, la libre negociación de las acciones es admitida ya en el capítulo primero de la compañia en el que se dispone que aquéllas “...podrán los interesados venderlas o cederlas, pero no extraherlas de ninguna forma de compañia...". Es decir, lo que no se admite es la detracción del fondo, que deberá continuar en la compañía durante los nueve años previstos para su duración, pero sí la libre negociación. Esta queda regulada en otros capítulos para atender a las dos posibilidades básicas de enajenación: la transmisión hereditaria y la venta o cesión. En el primer aspecto, la transmisión por fallecimiento de los socios, se admite sin ningún tipo de dudas, pues en el 
capitulo primero se dispone que «...en caso de fallecimiento podrán los herederos continuar en la compañía, o vender o ceder las acciones...". Además, en el caso de que los herederos sean viudas de los socios se les deja en entera libertad para continuar o no en la compañia, quedando ésta obligada en el último caso a comprar las acciones, según se dispone en el artículo $35 .^{\circ}$ :

"Además de lo advertido en el capítulo primero, se declara que si falleciere alguno de los interesados en esta compañía y la viuda no quisiere continuar ni dejar en ella la accion, o acciones, que tenga del difunto, las deberá comprar la compañia según el estado de lo que hayan producido en el fondo, y lo que haya resultado del último vilanze y ajustamiento que se haya hecho del año antecedente, quedando en la masa común de la compañía las ganancias que en el año corriente correspondan a aquellas acciones. Pero si quisiere esperar a sacar la acción o acciones hasta el último año, en que se arreglan las cuentas generales, se la dará todo el haber por entero; y esto sólo se debe entender con las viudas; y siendo otros los herederos se observará literalmente lo prevenido en los capítulos primero y quinto...”

Por tanto, la transmisión hereditaria de la acción queda enteramente garantizada en la compañía estudiada. Por lo que respecta al otro tipo de transmisión, la venta o cesión de acciones, también queda permitida, aunque con algunas restricciones, según se dispone en el capítulo quinto:

"...Antes de vender los interesados la acción, o acciones, que tengan en la compañía, darán aviso a los Directores de ella, y éstos harán Junta de los demás interesados para ver si hay dinero en el fondo de ella para comprailas, si pareciere a todos conveniente; $y$ en caso de no, serán privilegiados por el tanto aquél o aquéllos que quieran comprarlas de la misma compañia. $Y$ no queriendo la compañia, ni los interesados en ella, podrán hacer ajuste con la persona que le convenga, con tal que sea de la aprobación de los cinco empleados, con la advertencia que, no siendo librero o impresor en quien recaiga la 
acción, o acciones, no tendrá voto en la compañía, ni podrá obtener empleo en ella, y solamente se les convocará en el dia señalado para el ajuste de cuentas...".

Como se puede ver, la compañia sólo se reserva la posibilidad de quedarse la acción o de que alguno de sus miembros use del derecho de tanteo, quedando en caso contrario en libertad de poderse vender la acción con la única limitación de la previa aprobación de los cargos directivos para la persona adquirente.

Podemos concluir, en este aspecto, que la compañía estudiada tiene una clara orientación capitalista en sus estatutos, ya que convierte a las acciones en unos valores de riqueza mobiliaria fácilmente transferibles, con lo que la inversión realizada se podría recuperar cuando se desease. Este hecho confiere un enorme grado de modernidad a esta compañia, aventajando incluso a las, por otra parte más tardias, compañías privadas de seguros existentes en Bilbao, en las que no se admitia ningún tipo de negociación de la acción(13), y en Cádiz, en las que sólo en la compañia de Nuestra Señora de las Mercedes de 1777 se admitia la posibilidad de negociación(14). Esta naturaleza capitalista de las acciones si existe, sin embargo, en el caso de la compañía de impresores y libreros de Madrid'(15), y en muchas de las compañias privilegiadas, según señala Martinez Gijón(16).

El otro rasgo diferenciador de las sociedades anónimas con respecto a las compañias anteriormente existentes es el grado de responsabilidad limitada de los socios frente a las deudas sociales existentes en aquéllas. En el caso de las compañías generales, los socios eran responsables solidariamente, es decir, sin importar la entidad del capital que hubieran invertido en la sociedad, e ilimitadamente, con la totalidad de sus bienes, frente a los acreedores. Ciertamente, en el caso de las compañias comanditarias el socio comanditario sólo respondia con el capital que hubiese puesto y las ganancias que con él hubiese acumulado. Sin embargo, en estas sociedades siempre debian existir socios "Colectivos" que seguían responsables con la totalidad de sus bienes(17). Por tanto, la gran novedad aportada por las compañías por acciones consiste en que todos los socios, y no sólo una parte de ellos, asumen una responsabilidad limitada. A pesar de todo, parece que esta limitación sólo se presenta en los siglos XVII y 
XVIII con un carácter excepcional en las compañías coloniales de Holanda, Inglaterra y Francia. Y según señala F. Galgano(18), el carácter excepcional derivaba de que éstas sólo se formaban por un acto de concesión real, la cual establecia el "privilegio" de la limitación de la responsabilidad, derivada de la importancia que la explotación colonial tenia para el estado mercantilista. Asi Levy-Bruhl señala que en las sociedades de capitales francesas esta norma no comenzó a generalizarse sino a partir de 1780 , rigiendo hasta entonces el principio de responsabilidad ilimitada(19). En el caso de España, parece que sólo ha aparecido hasta ahora una sociedad con limitación de responsabilidad, la Compañia de Nuestra Señora de las Mercedes, establecida en Cádiz en 1777(20). Sin embargo, ni en el resto de las sociedades de Cádiz y Bilbao, ni en las propias compañías privilegiadas estudiadas por Martínez Gijón(21), se establece aquella cláusula. Algo similar ocurre en la compañia aquí estudiada, puesto que ninguno de sus capitulos se refiere a esta cuestion. Cabe, pues, suscribir la tesis de Martínez Gijón en el sentido de que “...es evidente que, si se hubiese querido limitar la responsabilidad de los socios, no podía faltar una cláusula que así lo estableciese...". Pero, además, el acta de compañia no deja de recoger una coletilla final que suele ser común a la mayor parte de los contratos, pero que en este sentido es muy sintomática, ya que en ella los socios, "...para au seguridad y puntual observancia y cumplimiento (del acta de compañia) obligaron sus personas y bienes habidos y por haber...». Resulta, pues, evidente que en esta sociedad los socios seguian teniendo una responsabilidad ilimitada frente a los acreedores.

Cabria concluir, por tanto, que la compañia de libreros e impresores establecida en Valencia en 1759 contiene uno de los rasgos fundamentales que caracterizan a las futuras sociedades por acciones: la ausencia del personalismo, adoptando, en cambio, una clara orientación capitalista en sus estatutos. Sin embargo, la no presencia del otro rasgo caracterizador (la responsabilidad limitada) impide que sea definida completamente como una sociedad anónima. Se trata, sin duda, de una compañía que se enmarca en un periodo de transición, en el que van progresivamente adoptándose las características que diferenciarán a las sociedades de capitales más representativas de la actualidad. Ahora bien, estas reflexiones se basan simplemente en la forma de asociación adoptada, y no en la enverga- 
dura que realmente tuvo la compañía. Esta fue, en realidad, muy modesta, puesto que el valor de cada acción se cifraba en 50 Libras (capítulo primero), exactamente la mitad del que cuatro años después se fijaba en su homónima de Madrid, y el capital total suscrito por los ocho primeros socios fue de 1000 Libras, aunque en sus capítulos $4 .^{\circ}$ y $5 .^{\circ}$ se preveían futuras ampliaciones de capital. Desde luego, para calibrar exactamente estas cifras hay que ponerlas en relación con el coste de edición que tenían los libros en el siglo XVIII. Al respecto, M. ${ }^{a}$ Fernanda Mancebo señala que "...las tiradas son cortas, oscilan entre 300-no comercial-y 1.500... Los precios van de 2 libras - un libro caro-a 8 dineros, las "oraciones" de la Academia, pero están en función del número de páginas....»22). La misma autora, utilizando la liquidación de las obras impresas por la Academia Valenciana, señala el precio de algunas obras concretas: 13 sueldos la "Era..." del Marqués de Mondejar, 6 sueldos las "Advertencias al P. Mariana..." y 3 sueldos los "Avisos del Parnaso" del Dr. Corachán. Por tanto, aún con estos datos aparece como muy escaso el capital conseguido por la compañía en su primera suscripción de acciones, por lo que cabe relacionar este hecho con el débil poder económico de los socios. Así, a pesar del pequeño valor de las acciones, en el capítulo tercero se disponía que en los dos primeros años se admitiría en pago de aquéllas el valor de impresiones ya hechas. Y la compañía de impresores y libreros de Madrid era mucho más explicita en este asunto cuando, al disponer en su capítulo quinto un mecanismo similar, señalaba: "...Que siendo tan vasto el comercio de los libros, por las muchas obras que se pueden imprimir de todas fa.cultades, y en que se necesitan emplear crecidos caudales, y al presente no hallarse algunos de los impresores con los suficientes para interesarse de pronto en esta compañía...,(23). Todo ello nos obliga a concluir que fue quizás el escaso poder económico de los socios el que determinó la pequeña envergadura que tuvo realmente la empresa, lo que no fue obstáculo para que aquéllos adoptaran una forma de asociación que contenía algunos de los rasgos fundamentales de la futura empresa capitalista.

Pero no basta el análisis de la forma económica de la sociedad. Tratándose de una empresa editora, era necesario un proyecto intelectual que encuadrase las impresiones. $Y$ la "Compañia de libreros y impresores de Valencian tenia muy claras las ideas al respecto. El 7 de febrero de 1760 
Juan Antonio Mallén y Manuel Cavero, «mercaderos de libros..., en nombre y como directores que son de la Compañia", com narecen ante el escribano público y de número de la ciudad de Valencia y de la subdelegación de imprentas y librerías, Miguel de Robles y Cisneros. La visita estaba orientada a otorgar todos sus poderes en favor de Pedro de Rueda Osorio, procurador de los Reales Consejos, con el fin de conseguir del Consejo de Castilla la licencia para imprimir una serie de libros que a continuación señalo:

"Los tres tomos, en quarto, Corona Gótica de Dn. diego Saavedra.

Las Empresas políticas, por el mismo author.

La República Literaria, por el propio author.

Los dos libros de las Epistolas selectas de Cicerón con traducciones y declaraciones en lengua castellana, por Pedro Simón Abril.

Reglas de orthografía en lengua castellana, por el maestro Antonio de Nebrija, añadidas algunas reflexiones por Dn. Gregorio Mayans y Siscar.

Accussationes in Verrem liber primus, qui Divinatio dicitur, cum interpretatione hispana et scholiis Petri Simonis Aprilei, un tomo en quarto.

Las Seis Comedias de Publio Terencio, traducidas de latin en castellano por Pedro Simón Abril, con la vida del mismo poeta y los argumentos de su comedia, su author Elio Donato y traductor el mismo Abril, un tomo en octavo.

Las Geórgicas de Virgilio, traducidas de latín en lengua castellana en versos sueltos por Juan Guzmán, con anotaciones del mismo y va añadida la traducción de la primera Géórgica por el maestro Fr. Luis de León, de la orden de San Agustín, un tomo en dozavo.

Obras de Cayo Crispo Salustio, traducidas de latín en castellano por Emanuel Suerio, añadidas las oraciones de Ciceron contra Lucio Sergio Catilina traducidas de latín en lenga espa- 
ñola por el Dr. Andrés Laguna, médico de Julio tercero, pontífice máximo, un tomo en octavo.

Obras propias y traducciones latinas, griegas y italianas con la paráfrasi de algunos psalmos y capitulos de Job, su author el doctíssimo y reverendísimo padre Fr. Luis de León del orden del grande doctor y patriarcha Sn. Agustín, un tomo en diez y seisavo.

La Eneyda de Publio Virgilio Marón, traducida en octavas rimas y verso castellano por el Dr. Gregorio Hernández de Velasco, en octavo.

Los quince libros de los Metamorphoseos de Publio Ovidio Nasón, traducidos en verso suelto y octava rima por Antonio Pé. rez, con sus alegorias al fin de cada libro.

Y los Emblemas de Alciato, traducidos de latín en romance español por Dn. Gregorio Mayans y Siscar»(24).

El texto muestra una línea de pensamiento claramente definida. El predominio absoluto de los autores clásicos latinos, traducidos por los humanistas españoles, resulta evidente. Respecto a los autores españoles sólo aparecen Saavedra y Nebrija y, como excepción, la traducción de Mayans de los Emblemas de Alciato. ¿Cómo se llegó a este esquema tan perfilado?. El único intelectual coetáneo, que aparece en el catálogo, puede explicarnos el proceso de tales proyectos.

Dado el carácter y la actividad intelectual de Mayans, resulta lógico que mantuviera estrechas relaciones con los impresores castellanos, extranjeros y, sobre todo, valencianos. Entre estos últimos sobresale Antonio Bordazar que mantuvo con el erudito una larga y duradera amistad con implicaciones culturales y, por supuesto, dentro de los problemas editoriales. Bordazar publicó muchas de las obras de Mayans o preparadas por el erudito, como la Censura de historias fabulosas de Nicolás Antonio, y fue nombrado impresor de la Academia Valenciana(25). Pero las relaciones de don Gregorio con la "Compañía de libreros e impresores" no vino por Bordazar, muerto en 1744, ni por su viuda o yerno (Tomás Santos), aunque formaba parte de la Compañía, ni por Antonio Balle, otro de los impresores que habian publicado con anterioridad obras del erudito. Ni siquiera 
Benito Monfort, que trabajara en la imprenta de Bordazar, dirigió las conversaciones culturales con Mayans. Esta gestión estuvo encomendada a Juan Antonio Mallén y, sobre todo, a Manuel Cavero, los dos más importantes accionistas junto con Salvador Fauli. No deja de llamar la atención el hecho de que los tres más importantes accionistas fueron "mercaderes de libros", mientras los "impresores" contribuyeron con menor cantidad de dinero.

Ahora bien, Mayans conocía a Mallén y a Cavero desde muchos años antes. La primera carta, que he localizado, de Mallén a don Gregorio es de 1746. En ella comunicaba que le habian llegado las obras de Van Espon solicitadas por el erudito, al tiempo que pedía instrucciones sobre su encuadernación(26). Dos años después, en 1748, Mallén se convertía en el intermediario entre Mayans y el editor de Ginebra Cramer, aunque, a decir verdad, una vez entregó el paquete a la Inquisición para salvar sus intereses, por si el paquete contenía libros prohibidos(27). No obstante, don Gregorio continuó enviando su correspondencia y sus libros a Cramer por medio de Mallén de quien se servía, asimismo, el editor ginebrino. No deja de constituir un sintoma de la confianza alcanzada entre los dos hombres de negocios el hecho de que Cramer enviara a Mallén tanto su dirección de Ginebra como la del duque de Choiseul en Versailles, por si Mayans queria enviar "algún pliego" a Voltaire(28). Por lo demás, nuestro librero tuvo relaciones con Francisco Grasset, otro editor ginebrino, con quien trató en 1762 cuando Grasset se dirigia a Oliva, acompañado de Antonio Capdevila, para visitar a Mayans.

Según la correspondencia que conozco, Mayans empezó sus relaciones epistolares con Cavero en 1749. Mallén y Cavero se dirigieron al erudito, solicitando consejo para editar un libro que tuviera éxito y venta. Determinar un buen libro era fácil pero mayor dificultad entrañaba la exigencia de que alcanzara una gran venta. De cualquier forma, Mayans se atrevió a aconsejar las Selectas de Cicerón traducidas por Simón Abril(29). A los libreros les encantó el consejo, aunque insinuaban la escasa salida que alcanzaria "si no se da en las aulas"; más todavía ante el hecho de que los jesuitas habian editado un "Ciceronet" para sus aulas, suficiente razón para disuadir a los alumnos de su compra. 
Sin embargo, Cavero comunicaba a Mayans, en 1758, su deseo de editar las Crónicas de los Reyes de España y solicitaba información. Y el erudito expuso con amplitud su pensamiento. Se despacharían bien, pero están viciadas con lo que pierden todo valor. $Y$ a continuación enumera la crónicas: Historia General de España de Alfonso el Sabio (1541), Crónicas de Alfonso el Sabio, Sancho el Bravo y Fernando IV (1554), Crónica de don Pedro, Enrique II y Juan I por Pedro López de Ayala con las enmiendas de Zurita (1591) y (1682), Crónica de Juan II (1547), Crónica de los Reyes Católicos por Fernando del Pulgar (1567). Naturalmente, Mayans no cree que deben editarse utodas a un tiempo, por no exponerse a perder tocia la impresión, sino ofrecerlas todas i ir publicándolas sucesivamente». En cualquier caso, es necesario un método crítico como el usado por el marqués de Mondéjar en las Memorias del rei D. Alonso el Noble i del rei D. Alonso el Sabio. "Es lo mejor en su género. Si Vd. quiere imprimirlas, yo las franquearé, que soi el único que las tiene».

Decidido a exponer sus ideas, el erudito indica la conveniencia de publicar la Historia del P. Mariana en latín y castellano, la explicación de la parábolas del Evangelio por Fr. Juan de Granada, las Empresas de Saavedra Fajardo también bilingüe. Finalmente encarga a Cavero que devuelva al regidor de la ciudad de Valencia, Benito Escuder, “las Epistolas de Abril... i yo se las embiaré siempre que quiera reimprimirlas (30). No deja de llamar la atención el hecho de que ofrezca, en nombre de un amigo, la Historia eclesiástica de Dupin, en 19 tomos, libro prohibido, por si Cavero desea comprarla.

Quisiera hacer dos precisiones. El proyecto de editar las Crónicas quedó al margen de los intereses de Cavero y no entrará en los planes de la Compañia de libreros e impresores. En cambio, es conveniente observar el interés del erudito por las ediciones bilingües latino-castellanas: Mariana, Saavedra y, sobre todo, las Epístolas de Cicerón según traducción de Simón Abril, que ya habia prestado con anterioridad al librero.

Cavero debió quedar satisfecho de semejantes planes y Mayans aprovechó la ocasión para exponer su idea sobre ediciones de autores castellanos, no sin antes precisar el proyecto de la Historia del P. Mariana. Y, entre los clásicos de nuestra literatura, propone las obras de Góngora con los 
comentarios de Salcedo Coronel y Salazar Mardones, Lecciones solemnes de Pellicer, Juan de Mena con la glosa del Comendador Griego y las notas del Brocense, Garcilaso con sus comentadores (Brocense, Fernando Herrera y Tamayo Vargas). Y añade: "yo puedo ofrecer la traducción que hice de los Emblemas de Alciato, i no seria mui costoso hacer abrir las láminas, aunque no fuessen mui delicadas". A Mayans se le ofrecian "mil cosas" que serían "utilissimas al público» y al editor, "si en España huviera más amor a las letras»(31).

Eran proyectos expuestos al mercader de libros que no entrarían en los planes de la Compañia de libreros e impresores, excepto los Emblemas de Alciato. No será ocioso señalar, sin embargo, que Benito Monfort, uno de los socios, haría años después una espléndida impresión de la Historia de P. Mariana.

Ahora bien, apenas firmados los capítulos de constitución de la Compañía, Cavero escribe de nuevo a Mayans. Se presenta como quien lleva la iniciativa y sus ideas son ambiciosas. "En fin, yo soy el que llevo el timón de la Compañía y espero que, ayudado de un piloto tan docto y experimentado como $V$., saldré a puerto seguro y se verá en España renacer el buen gusto en las impresiones imitando a los Moretos, Manutios y Griphos, y si alguna vez no sigo en todo los consejos de $V$. será porque no pende de mí solo el poner en práctica los sabios pensamientos de V." (9-11760).

Dejemos de lado la posible divergencia entre los socios de la Compañía insinuadas por Cavero. De cualquier forma, en la carta aparecen dos grandes líneas proyectadas. De un lado, los clásicos latinos con la traducción castellana de Simon Abril: "he propuesto a estos señores el hacer la reimpresión de Terencio de Abril, de las Epistolas selectas del mismo y de las Fábulas de Esopo, y quedó acordado en la Junta el que se imprimiesen, por lo que he de deber a $V$. me remita dichos libros sin dilación alguna para sacar las licencias...". En otras palabras, Cavero propone, los socios aprueban la propuesta y Mayans, padre de la idea, aporta los textos. En esa línea hay que incluir la pregunta de Cavero sobre el estado de la traducción mayansiana de los Emblemas de Alciato, "como también el Virgilio con la traducción de Fr. Luis de León, si es cosa que se pueda 
imprimir, luego me podrá V. remitir los originales». Estamos en la perspectiva trazada por don Gregorio de editar textos bilingües que facilitasen el conocimiento de la lengua del Lacio. Por lo demás, el lector habrá podido observar que todas esas obras aparecen en la entrega de poderes a Rueda Osorio para solicitar del Consejo de Castilla la licencia de impresión.

En cambio, aparece otra serie de libros cuya edición se emprendería al finalizar la de las traducciones de Simón Abril: Saavedra Fajardo, Bibliotheca Musarum..., "Historia Universal de Bossuet continuada hasta nuestros tiempos y los Rudimentos Históricos". Cavero observa que en la impresión de estos libros no buscan tanto el "buen gusto" como el «despacho", aspecto que una compañía comercial debe tener en cuenta. No hace falta insistir en que, excepto Saavedra, ninguno de estos autores aparece en el catálogo de libros cuya licencia de impresión se solicitaba del Consejo de Castilla(32).

¿Cómo explicar la victoria de la línea humanista en los proyectos de la compañía?. Sin las actas de la Compañia de libreros e impresores, resulta difícil ver los pormenores. Pero los datos que nos aporta la correspondencia conservada nos permiten conjeturar que el interés de Cavero y los consejos de Mayans inclinaron la balanza. El 9 de enero de 1760 escribía Cavero: "...y yo por mi voto (y espero conseguirlo) haría una colección de todas las obras de Nebrija, de Sánchez (de las Brozas) y de Vives y con especialidad de todos los poetas antiguos castellanos». No poseo la respuesta de Mayans que debió ser calurosa y efusiva. Así se deduce de las palabras de Cavero en el correo siguiente al especificar las obras que solicitaba del erudito: Ortografia de Nebrija, Introductio ad Sapientiam de Vives, la Divinación de Cicerón, Emblemas de Alciato, Oraciones de Cicerón, Eglogas de Virgilio en versión de Fr. Luis de León, Geórgicas traducidas por Juan de Guzmán y la Eneida por el Dr. Hernández de Velasco, la Guerra de Yugurta en traducción de Sueiro y la Poética de Horacio por Esquivel(33). Tenemos aquí otro bloque de autores incluidos en el catálogo presentado al Consejo de Castilla. Y que tal proyecto era idea mayansiana se desprende de las palabras de Cavero: "In continenti que V. me las embie vacaré las licencias para su impresión y aseguro a $V$. el que se procurará salgan hermosas y correctas impresiones i le doi a $\mathrm{V}$. las gracias de las noticias que me franquea e igualmente todos los demás compañeros...”. 
Este juicio aparece confirmado por los hechos. A vuelta de correo, Mayans comunica no sólo el envio de algunos libros, sino también el estado de su trabajo intelectual que debe acompañar las ediciones. "Ayer embié a Vm. la Ortografía de Antonio de Nebrija, las Selectas de Cicerón traducidas por Abril i las Fábulas de Esopo por el mismo. Tengo hecha la Prefación para las Selectas, pero no está copiada. Haré presto la otra para las Fábulas»(34).

Era la manera de impulsar las ediciones. Pronto enviará los Emblemas de Alciato traducidos señalando una serie de normas a seguir en el texto bilingüe y las láminas. Don Gregorio ofrece, asimismo, las Empresas, Corona Gótica y República literaria de Saavedra, Terencio traducido por Simón Abril, Introductio ad sapientiam de Vives en versión de Astudillo, "que tengo que es mejor que la de Cervantes de Salazar más antigua, que también tengo, con más de 200 traducciones de griego i latín de que hemos de inundar España". No hace falta recordar que todos esos autores pueden verse en el catálogo de obras cuya licencia de impresión se solicitó al Consejo de Castilla.

Dado que Cavero hablaba de su interés especial por los «poetas antiguos castellanos», don Gregorio insinúa la conveniencia de hacer públicos una serie de autores: el Quijote, el Monserrate de Virués, Juan de Mena, Jorge Manrique, el Anfitrión de Villalobos, Villegas, Maestro Pérez de Oliva, Heliodoro de Juan de Vergara, Mondéjar. Y añadia la Poética de Aristóteles y Pomponio Mela ilustrados por González de Salas, la Ibis de Ovidio del Brocense, Tácito traducido, Cesar en castellano... Se trataba, realmente, de un plan ambicioso, pese a que el erudito expresara su realismo: "Ninguna propuesta haré que sea para la República de Platón, sino para adelantar las ciencias i que Vmdes. ganen dinero". No obstante los socios de la Compañia no los incluyeron en esa lista que sabemos fue enviada al Consejo para solicitar la licencia de impresión. Las razones de esa solicitud global aparecen en carta de Cavero, al exponer su interés por tener aprobadas todas las obras: "el motivo es el sacar las licencias del Consejo de una vez para no repetir gastos".

La creación de la Compañía debió suscitar una ola de entusiasmo entre los miembros. $Y$ las gestiones iniciales parecian demostrar gran eficacia. 
En abril de 1761, Cavero enviaba a Mayans, en nombre de la Compañía, 6 ejemplares de las Selectas de Cicerón y otros tantos de las Fábulas de Esopo. Era el primer fruto y, decia, "logran el aplauso de los curiosos y azen ver el buen gusto i elección de V.". Más todavia, por esas fechas, estaban en prensa las obras de Terencio, el discurso de Cicerón contra Verres y las poesias de Fr. Luis de León habían sido enviadas a Madrid para conseguir la tasa y la fe de erratas del Consejo. Hay, sin embargo, una frase en la carta de Cavero que puede expresar diferencias de criterio entre los socios: "La Ortografia de Lebrixa, Vives i demás obritas se irán imprimiendo, pero es preciso contemporizar con los compañeros que se prometen en las otras más despacho, pero no dexarán de imprimirsex(35).

Mayans recibió con inmenso júbilo la edición de las Selectas y de las Fábulas y aprovechó las circunstancias para insistir en la importancia de continuar la tarea emprendida, especialmente en la Introductio ad sapientiam de Vives. "Deseo ayudar a Vm. i a sus compañeros en sus buenas ideas de propagar las letras»(36).

A lo largo de ese año 1761, mientras Mayans redacta los prólogos al Arte poética de Horacio, al Discurso de Cicerón contra Verres y a Terencio(37), surgen las primeras divergencias con motivo de la edición de la obra poética de Fr. Luis de León. Frente a la idea mayansiana de publicar el texto paralelo latino-castellano, y una cuidada edición de la poesia original, la prisa de los socios de la Compañia complicó las cosas. La intervención de Vicente Blasco, autor de las Observaciones y la redacción, a últíma hora, de la Vida de Fr. Luis por parte de Mayans resolvieron aparentemente las diferencias con los impresores. Por lo demás, la edición contribuyó a difundir la fama del agustino como uno de los mejores poetas de la historia de la literatura española(38).

Pese a tales diferencias, las relaciones no se interrumpen. Mayans cumple sus compromisos y redacta los prólogos a las obras de los clásicos y humanistas que edita la Compañía. Pero las publicaciones fueron distanciándose. Apareció el discurso ciceroniano contra Verres (1762), Terencio (1762), Ortografia de Nebrija (1764) y la Introductio ad sapientiam según la versión de Astudillo (1765) que Mayans dedicó al conde de Aranda, por esas fechas Capitán General de Valencia. 
De cualquier forma, las relaciones de don Gregorio con los socios de la Compañía adquieren un carácter cada vez más personal. Es cierto que Cavero comunica la edición de la Ortografía de Nebrija y el interés por hallar el Arte poética de Horacio que había extraviado el portero del Consejo de Castilla(39). No obstante, poco a poco se imponen los temas de Cavero como mercader de libros: transmite un paquete de libros que enviaba Grasset para el erudito(40), lleva a cabo gestiones para el envío a Madrid de las Memorias históricas del rey don Alonso el Sabio de Mondéjar, pero rechaza la oferta de Mayans para encargarse de vender Novus thesaurus iuris civilis et canonici de Meerman porque es obra "erudita pero de corto despacho para este país, pues con media docena de exemplares ai suficientes para los pocos que siguen los consejos de $\mathrm{V}$. a quien tanto deve la nación, i así no me está a cuenta el cambio que aquel señor desean(41). Y no sería el primer abandono por parte de Cavero de una relación con intelectuales europeos propiciada por Mayans. Porque el 12 de octubre de 1762 el erudito anunciaba el recibo de un paquete de libros que, por medio del librero, le enviaba Fernando Hommelio y un discurso de Juan Rodolfo Iselín. Ahora bien, Iselín comunicaba la edición en Basilea del Glossarium mediae et infimae latinitatis de Ducange y solicitaba el nombre de libreros que despacharan la obra. Empresa que no encontró acogida favorable(42).

No fue Cavero el único miembro de la Compañía que mantuvo relaciones editoriales con Mayans. Aparte de J. T. Orga, que imprimió la obra poética de Fr. Luis de León, y Benito Monfort la Ortografía de Nebrija (en nombre de la Compañía en los dos casos), Monfort editó, por su cuenta, la Carta del erudito contra el pavorde Vicente Calatayud (1760) y la Oratio de optima ratione philosophiae (1763). asimismo, Fauli (habia entrado en la Compañia como mercader de libros y con posterioridad montó su imprenta) publicó las Cartas morales mayansianas (1773) y la Lección christiana de Arias Montano en su segunda edición (1771).

Hay un hecho que merece nuestra atención. La mayor parte de los libros publicados por Mayans posteriores a 1765 lo fueron por impresores que no formaron parte de la Compañia: Orga (6 titulos), Burguete (8) y Dolz (2). Opera omnia de Vives, publicada por Monfort, no tiene significación pues, además de que el pago corria por cuenta del arzobispo Fabián y Fuero, su impresión fue iniciada en 1782, después de la muerte de 
don Gregorio. Dicho con otras palabras, no parece que Mayans mantuviera muy cordiales relaciones con los socios de la Compañia después de 1765 en que apareció la Introductio ad sapientiam de Vives.

En un intento de explicar el fracaso de la Compañia de libreros e impresores de Valencia, yo señalaría dos razones fundamentales. En primer lugar, el carácter de los socios, con predominio de los mercaderes de libros, resulta más evidente si óbservamos el capital social. Mientras los libreros imponen 16 acciones con un capital real de 800 libras, los «impresores" sólo poseen 4 acciones con un capital de 200 libras. Esta composición explica que la dirección efectiva esté en manos de los «mercaderes de libros". Mallén y, sobre todo, Cavero. Y es muy posible que en esa dualidad haya que buscar la raíz de las divergencias en los proyectos a que antes aludíamos.

Pero hay una segunda razón nada desdeñable. Uno de los socios más jóvenes y, quizás por esas fechas, menos dotados económicamente era Benito Monfort. Habia sido oficial en la imprenta de Bordazar y acababa de establecerse en su taller propio (1757). El concepto que tenía Cavero del joven impresor no era muy halagüeño: "Benito Monfort es mui pobre de espíritu i veré el modo de que la impresión de la Introducción a la divina sabiduría pare en mi poder que yo la daré salidas(43). Puede que en ese error de juicio radiquen muchas de las dificultades de la Compañía. Por lo demás, sus conocimientos técnicos lo colocaban en un plan de superioridad respecto a los «mercaderes de libros» que se arrogaban la dirección de la empresa.

Más todavía, el mismo año 1759 en que se fundaba la Compañia, se establecia en Valencia José Tomás Orga, hijo de José Jaime, que, como Monfort, habia trabajado en el taller de Bordazar y habia mantenido relaciones amistosas con Mayans. José Jaime abandonó la ciudad para trabajar en Salamanca y Madrid pero, a su muerte, la viuda y su hijo José Tomás volvieron a Valencia donde establecieron sus prensas. Dada la experiencia y cualidades, pronto se convirtió Orga en uno de los mejores impresores de la ciudad, alcanzando, junto con Monfort; una superioridad innegable.

En esas circunstancias, los proyectos impresores de la Compañía estaban en peligro. La presencia en la ciudad de un competidor (Orga no formaba parte de la Compañia) y la capacidad de un socio como Monfort que 
podia desenvolverse con éxito de forma individual debieron provocar fuertes tensiones. Sólo una venta espectacular de los libros impresos podía salvar la Compañía. Pero esto, pese a los deseos de Mayans, era imposible. $Y$, en el fondo, el erudito lo sabía. Por eso insistía tanto en la necesidad de que continuaran uel beneficio público sacando a la luz muchas (obras) semejantes, que faciliten el conocimiento de la lengua latina, i vayan introduciendo el buen gusto, sin el qual no se puede esperar que se estimen los librosw(44).

Era quizás pedir demasiado en un país donde el humanismo, como ha puesto de relieve Luis Gil en un libro reciente, nunca ha gozado de la comprensión de la sociedad ni del apoyo del poder. Una razón más que viene a explicar el hundimiento de la Compañia que habia centrado sus primeros pasos en la edición de los clásicos latinos con las mejores versiones castellanas, en un intento, propiciado por Mayans y el ambiente intelectual valenciano del momento, de introducir el humanismo en el mundo intelectual español del XVIII.

\section{NOTAS:}

(1) Carlos Petit ha estudiado en Bilbao unos 260 contratos de compañía comprendidos entre 1737 y 1829 , y señala que el $90 \%$ de los mismos eran compañias "generales" y el $8 \%$ comanditarias. PETIT, C. La compañia mercantil bajo el régimen de las Ordenanzas del consulado de Bilbao. 1737-1829. Sevilla, 1979. pp. 49 y 49.

(2) J. MARTINEZ GIJON, "Las sociedades por acciones en el derecho español del siglo XVIII". En revista del Instituto de Historia del Derecho, n. ${ }^{\circ}$ 19. Buenos Aires, 1968. p. 68.

(3) F. GALGANO, Storia del diritto commerciale. Bolonia, 1976. pp. 62-67.

(4) P. VILAR, Catalunya dins I'Espanya moderna Tomo IV. La formació del capital comercial. Barcelona, 1968. pp. 537-540.

(5) A. GARCIA BAQUERO, Cádiz y el At/ántico (1717-1778). Sevilla, 1976. p. 413.

(6) PETTIT, 59-65.

(7) E. LARRUGA, Memorias politicas y económicas sobre los frutos, comercio, fábricas y minas de España, con inclusión de los Reales Decretos, ordenes, cédulas, aranceles y ordenanzas expedidas para su gobierno y fomento. Vol. III. Madrid, 1787. p. 225.

(8) A.R.V. Protocolos. Sig. 7.632. Año 1759. fol. 73 v. 
(9) LARRUGA, 225.

(10) PETIT, 158.

(11) ID., 49-56.

(12) MARTINEZ GIJON, p. 72.

(13) PETIT, 65.

(14) GARCIA-BAQUERO, 418-420.

(15) LARRUGA, Capitulo $4 .^{\circ}$.

(16) MARTINEZ GIJON, 80.

(17) PETIT, 199-210.

(18) GALGANO, 62-67.

(19) Citado en GARCIA-BAQUERO, 423.

(20) GARCIA-BAQUERO, 423-424.

(21) MARTINEZ GIJON, 89.

(22) M. F. MANCEBO, "Mayans y la edición de libros en el siglo XVIll". En Mayans y la ilustración. simposio Internacional en el bicentenario de la muerte de Gregorio Mayans. Valencia, 1981. p. 224.

(23) LARRUGA, 224-233.

(24) Poderes de los Directores de la Compańía de libreros e impresores de Valencia a favor de Dn. Pedro de Rueda Ossorio, procurador de los Consejos, ARV, Protocolos, libro núm. 7632.

(25) Sobre las relaciones Mayans-Bordazar, cf. A. MILLARES CARLOS, «Mayans y Feijoon, Revista de Filología española, (1923); J. A. TAMAYO, "Mayans y la Ortografía de Bordazar", Ibid XXV (1941); A. MESTRE, El mundo intelectual de Mayans, Valencia 1978; V. FERRAN SALVADOR; "Antonio Bordazar de Artazu. El impresor erudito (ensayo biográfico-bibliográfico)", Boletin de la Sociedad Castellonense de cultura, (1964) XL, 119-147, M. F. MANCEBO, Mayans..., J. E. SERRANO MORALES, Reseña histórica en forma de diccionario de las imprentas que han existido en Valencia..., Valencia 1898-1899.

(26) J. A. Mallén a G. Mayans, 28-IX-1746, Biblioteca Municipal de Valencia, Serrano Morales 6809-1. ${ }^{\circ}$.

(27) Id., 9-IV-1749, ibid.

(28) Id., 4-V!-1762, ibid.

(29) Mallén y Cavero a Mayans, 5-III-1749, ibid. 7270-28; Mayans a Mallén y Cavero, 8-III1749.

(30) Mayans a Cavero, 8-VII-1758, Biblioteca Archivo Hispano Mayansiano, 155.

(31) Id., 15-VII-1758, ibid.

(32) Cavero a Mayans, 9-1-1760, BMV, Serrano Morales 6807-2.․ Constituian la Compañia: Juan A. Mallén, Manuel Cavero Cortés, Salvador Fauli, Simón Faure, Pedro Miró, Tomás Santos, José T. Lucas y Benito Monfort.

(33) Id., 15-i-1760, IBID., 7263-11.

(34) Mayans a Cavero, 19-1-1760, BAHM, 161.

(35) Cavero a Mayans, 17-IV-1761, BMV, Serrano Morales 7263-11. 
(36) Mayans a Cavero, 27-IV-1761, BAHM, 161.

(37) Id., 15-Vl-1761, ibid.

(38) A. MESTRE "EI redescubrimiento de Fr. Luis de León en el siglo XVII"», "Bulletin Hispanique", LXXXIII (1981) 5-64.

(39) Cavero a Mayans, 21-XI1-1764.

(40) Id., 12-XI-1761, 6-X|I-1765, 24-I-1766.

(41) Id., 24-I-1766.

(42) Mayans a Cavero, 18-X-1762, BAHM, 161.

(43) Cavero a Mayans, 24-1-1766, BMV, Serrano Morales 7263-11.

(44) Mayans a Cavero, 27-IV-1761, BAHM, 161. 